\section{Positive Smear in Pregnancy}

SIR,-Mr. H. E. Reiss and Drs. J. A. U. Morgan and Margaret R. A. Utidjian are quite right (8 March, p. 641). Conization (also our routine apart from pregnancy) is a more complete method of investigating a positive smear than our cervical inspection and four-quadrant small biopsies. Over the period from 1958 to 1967 we have asked our patients in the interest of the baby to accept our advice, with the tiny risk that ill fortune had dealt what A. T. Hertig calls the "joker in the pack"-that is, not only carcinoma-in-situ but a tiny area of invasive, perhaps metastatic, carcinoma. Since 1966 we have added to our investigatory team J. A. Jordan, an expert in modern colposcopy, which uses subepithelial vascular patterns to locate abnormal epithelium. ${ }^{2-4}$ Small biopsies may be taken from target areas, but for the most part the dilatable pregnant cervix reflects the positive smear-namely, carcinoma-in-situ or epithelial dysplasia: these areas are now left alone until after delivery and planned conization eight weeks later.

May I pose two questions to colleagues who undertake routine conization in pregnancy?

(1) How often is pregnancy disturbed by this technique ? Manifestly loss of a potential child and at histology the presence of no more than epithelial dysplasia is a poor bargain.

(2) How often do you excise the epithelial lesion completely-that is, how often is postdelivery conization again indicated by persistently positive smears ?-I am, etc.,

\section{Hugh Cameron Mclaren. Department of Obstetrics and Gynaecolog
Maternity Hospital, \\ Birmingham 15 .}

\section{REFERENCBS}

1 McLaren, H. C., Prevention of Cervical Jordan, J. A., Practitioner, 1969, 351, 202.

S Koller, O., A Colpophotographic Study of the Vascular Patterns of the Uterine Cervix, 1963. Oslo, Universitetsforlaget.

4 Johanisson, E., Kolstad, P., and Söderberg, G., Acta Radiologica, 1966, Suppl. 258.

\section{Killing the Patient}

SIR,-Now that the debate on this subject in the Lords is over one presumes that the matter will be conveniently shelved for another 20 years. It is obvious that society in general and doctors in particular are not yet ready to reappraise their traditional attitudes to death.

Lord Raglan's Bill had sufferers from cancer particularly in mind. There is another category of irremediable condition to the solution of which society must sooner or later make a more constructive approach than at present. I refer to old age itself. Advances of medical science have made the attainment of extreme old age a commonplace. In these circumstances are we forever to refuse to intervene, leaving " nature to take her course" in regard to death, even though we may have intervened many times during the course of life by giving antibiotics, conducting operations, etc. ? We say in effect that death must always be due to disease or accident to be of natural cause. But is a voluntary death after the age of 85 so unthinkable ? Is not the ideal to be aimed at a disease-free life followed by a disease-free death ? If people were offered the option of euthanasia after the age of 85 I believe many would welcome it.

Medicine has made immense strides in the control of disease and is beginning to control birth, but death we insist on leaving to haphazard and fortuitous chance. With the prospect of remedies for such conditions as cancer and even atherosclerosis in sight it is high time we sought to replace instinct and prejudice in this matter by reason, logic, and humanity.-I am, etc.

Huddersfield, Yorks.

\section{S. L. HeNderson SMITH.}

\section{Anti-D Immunoglobulin}

SIR,-During the past year anti-D immunoglobulin has been available to the main maternity units in this region. To date 1,117 Rh-negative primigravidae have been given $200 \mu \mathrm{g}$. within 36 hours of the birth of an $\mathrm{ABO}$ compatible $\mathrm{Rh}$-positive infant. The blood of 320 recipients has been examined after the injection, and it is disturbing to find six apparently actively immunized.

The passively injected anti-D is detectable by enzyme methods only, but six women have antiglobulin titres ranging from 8 to 128 . In two of these cases immunization was suspected at the time of delivery by the detection of a weak anti-D by enzyme methods only, but the obstetrician decided to inject anti-D immunoglobulin. There are strong suspicions that one of these patients had had a previous pregnancy. In the four remaining cases the patients deny any previous pregnancy or transfusion, and there were no obstetric complications which might have resulted in a large foeto-maternal haemorrhage. One of these patients had no detectable anti-D at the time of delivery, but in the other three the serological tests had been performed at the 36th week of pregnancy and not at delivery. It is thus possible that anti$D$ was already present at the time of delivery.

A striking feature of these six cases of apparent active immunization is the rapid appearance of anti-D detectable by antiglobulin techniques. In four patients anti-D was detected six days after delivery, and in the remaining two six weeks post-partum These observations emphasize the need to test maternal serum for anti-D at the time of delivery, and also the importance of following up all recipients of anti-D immunoglobulin. -I am, etc.,

JOHN WALLACE.

\section{Glasgow and West of Scotland Blood Transfusion Service, Law Hospital Carluke, Lanarkshire.}

\section{Maternal Rh Immunization}

SIR,-In the otherwise excellent recent paper by Dr. W. Q. Ascari and others (15 February, p. 399) there is what I consider a serious error in logic. The error is very nicely summarized in the title of Table III "Comparison Between Expected and Observed Frequencies of Maternal $\mathrm{Rh}$ Immunization in $\mathrm{ABO}$ Incompatible Matings." What the authors have actually done is to compare the incidence of various ABO incompatible matings in a population of women who have $\mathrm{Rh}$ antibodies with the expected normal incidence of such matings of non-immunized women. They demonstrate a very appreciable reduction ( $31 \%$ to $49 \%$ in incidence of $A \times O$ and $B \times O$ (woman group $O$ ) matings, but by no means a complete abser.:e. They then proceed to use these figures to calculate that the incidence of immunization of group $\mathrm{O} R \mathrm{R}$-negative women by a single group A or B Rhpositive foetus is 9 to $12 \%$, as compared to $17 \%$ by a single $\mathrm{ABO}$ compatible $\mathrm{Rh}$-positive foetus.

What these authors failed to take into account is the fact that the husbands of many of these women doubtless were heterozygous (AO or BO), and that many of these women had doubtless previously delivered Rh-positive babies of group $O$. Actually, experimental efforts to immunize group $\mathrm{O} R \mathrm{Rh}$ negative volunteers to the $\mathrm{Rh}$ factor, using group A or group B Rh-positive cells, have not been particularly successful, and the antibodies observed were in most cases of very low titre. The present authors themselves point out that "cases of $\mathrm{Rh}$ haemolytic disease tend to be less severe where dual ( $A B O$ and $R h$ ) incompatibility exists between mother and infant."

There can be no question that the development of $\mathrm{Rh}$ immunoglobulin for the prevention of $\mathrm{Rh}$ immunization will eventually all but wipe out haemolytic disease of the newborn due to $\mathrm{Rh}$ immunization by pregnancy. It is by no means equally certain, however, that every Rh-negative woman who delivers an $\mathrm{ABO}$ incompatible $\mathrm{Rh}$-positive baby must be urged to receive an injection of this material. More detailed prospective analyses of incidence of $\mathrm{Rh}$ immunization among women who do not receive this material must be undertaken before the incidence of immunization by $\mathrm{ABO}$ incompatible foetuses is fully understood.-I am, etc.,

Paul G. Hattersley.

Sacramento Medical Foundation,

Sacramento, California, U.S.A

\section{Trichloroethylene Neuropathy}

SIR,-In the B.M.f. (15 February, p. 422), which I have just received, there is a medical memorandum on trichloroethylene neuropathy by Dr. A. B. S. Mitchell and Dr. B. G. Parsons-Smith. In this article they state that: "Trichloroethylene as an anaesthetic no longer produces neurological complications, but when used in industry the nervous system may be damaged. This is unlikely to be due to trichloroethylene itself, but may be due to breakdown products formed before inhalation, to metabolites formed in the body, or to triethylamine, which is used as a stabilizer in the industrial fluid but not in the anaesthetic fluid (Trilene)."

However, in the fifth edition of Lee's Synopsis of Anaesthesia in the section on "Trichloroethylene" the statement is made: "This danger [of toxic product formation] is much less with the brands of soda-lime now being used, which do not get so hot. The reaction to form dichloracetylene is much accelerated about $60^{\circ}$ C., whereas present-day soda-lime does not get much above $40^{\circ} \mathrm{C} . " 1$ 
Trilene anaesthesia is now used in a Mapleson A-type circuit or a non-rebreathing circuit, and therefore with a continuous flow of fresh gases the temperature will never rise above room temperature. In the case reported the patient was dipping the articles into a bath of warm trichloroethylene. The temperature of the bath is not stated, but since "fumes occasionally escaped in sufficient quantities as to be visible" the temperature must have been in the region of $60^{\circ}$ C. (Boiling point of trichloroethylene $87^{\circ}$ C.) This temperature in itself is surely sufficient to cause degradation into toxic products without incriminating the preservative. -I am, etc.,

\section{Department of Anaesthetics, Toronto, Ontario, Canada.}

REFERENCB

${ }^{1}$ Lee. J. A., and Atkinson, R. S., A Synopsis of Anaesthesia, 1964, 5th ed Bristol, John Wright.

\section{V.D. Patients and Contacts}

SIR,-A private member's Bill for compulsory treatment of venereal disease was withdrawn after opposition from both sides of the House of Commons on 21 March. $^{1}$ The annual figure for gonorrhoea now exceeds 40,000 experienced in 1930 and is rising steadily towards the peak of 47,300 seen in 1946. It is understandable that new legislation regarding contact tracing should be considered, but it should be related to the findings of a new question which could be introduced in the V.D. annual return.

Alcohol and a dark night are no aid to the patient seeking to identify his consort and give a clear description of her name and address to the clinician or social worker. Although tracing is encouraged and actively carried out, reliable statistics for the case of compulsory notification can only be based on those contacts with a clear name and address who refuse to attend a clinic. These were the contacts who were served with Form 2, and then on failing to attend were prosecuted under 33B during the war. A consensus of opinion could determine what would be an acceptable level of non-attending named consorts above which further action would be deemed necessary. I feel we should be able to stave off the threat of coercive legislation by rapidly implementing the spirit of the latest memorandum on Contact Tracing HM (68)84 by employing more V.D. social workers.-I am, etc.,

Rotherham, Yorks.

\section{A. L. Hilton.}

\section{REFERENCE}

1 Hansard, 21 March 1969, 780, No. 83, 144.

\section{Synacthen Depot in General Practice}

SIR,-We cannot let pass without comment the misleading letter from Dr. J. A. Weaver (8 March, p. 639).

Firstly, we did not, as he says, advocate the use of Synacthen depot "in a variety of 'rheumatic' disorders." We said that the results in our first 60 patients treated in general practice seemed interesting enough to report. We concluded by saying that the true value of the preparation in minor rheumatic conditions could not be assessed without a double-blind trial, which is now in hand.

Secondly, we too received, and happen still to have, the circular he complains about. Dr. Weaver quotes seven lines but omits the eighth, which reads ". . . and the results of controlled trials are awaited with interest." When read in full, it does not seem to us that the circular gives "very specific endorsement " to something we did not advocate in the first place.

Thirdly, he seems to have missed the point that for the minor rheumatic conditions we were using short courses of usually two to four injections. The question of long-term adverse effects does not arise, so that much of his argument is irrelevant. There is no difficulty about stopping Synacthen depot (as there may be with oral steroids), and many of our patients who have been incapacitated by previous attacks have been very grateful for the rapid relief. Far from encouraging its indiscriminate use, we are seeking to define the types of case for which it is justified, and our letter was by way of preliminary communication. Our longer courses of treatment were all in patients with established indications.

Finally, we would respectfully suggest that the incidence of side-effects that he has observed may reflect poor injection technique and inadequate attention to dosage. We have now treated nearly 100 patients, besides 25 so far in the double-blind trial, and our experience continues to be as stated in our letter.-We are, etc.,

\section{J. ERIC MURPhy. J. F. DONALd.}

Northampton

\section{Cerebellar Ectopia Presenting in Adult Life}

SIR,-The interesting article by Dr. Julius Smith and Dr. Alan Ridley (8 February, p. 353) prompts me to report a further patient with this condition, who presented at this department three years ago with pain and weakness in the right arm.

In June 1965 a 27-year-old woman noticed a prickling sensation in the right side of the neck, thumb, and index finger, followed by aching and "deadness" in the right arm and hand. Examination at this time revealed slight limitation of neck movements and no neurological abnormality. A radiograph of the thoracic spine showed upper thoracic kyphoscoliosis. A course of cervical traction was ineffective in relieving the symptoms. Three months later she noticed an odd sensation in the right side of the tongue and weakness of the right leg, and examination revealed increased deep reflexes in the right arm and leg, and right ankle clonus. The right plantar reflex was extensor and the left one equivocal. All abdominal reflexes were absent. There was impaired pain and temperature sensation, but not touch, in the $\mathrm{C} 2-\mathrm{C} 4$ dermatome bilaterally, but more on the right than the left.

Investigations were as follows: Radiograph of skull (including submento-vertical views), cervical spine and chest normal. C.S.F.: protein $100 \mathrm{mg} . / 100 \mathrm{ml}$., no cells; W.R. negative. Lumbar air encephalogram : no air entered the ventricular system, cisterna magna was small but no definite tonsilar protrusion was seen. Myodil ventriculogram: the fourth ventricle was low in position but did not reach to the foramen magnum. Films at 24 hours showed the contrast had left the fourth ventricle and was lying in the subarachnoid space; no definite tonsillar protrusion was seen.

A suboccipital decompression was carried out in February 1966 by the late Mr. J. V. Crawford. An Arnold-Chiari malformation was revealed. The cerebellar tonsils were elongated but thin: they reached down to the level of the axis, and were bound to each other, the medulla, and upper cervical cord by adhesions. Post-operatively there was marked improvement-she was virtually symptom-free, the deep reflexes were normally brisk and equal, and the plantar reflexes flexor. However, the right arm remained weak, and following a fall downstairs on to her neck and head both legs became progressively weaker and more spastic. In June 1967 the posterior fossa was re-explored, the laminae of $\mathrm{C} 2$ and $\mathrm{C} 3$ were removed, and several fibrous adhesions between the cerebellum and dura were divided. Unfortunately, the neurological signs have since worsened progressively and she is now severely spastic in all four limbs, though she is still able to work about the house with difficulty and can just about manage stairs.

This case illustrates cerebellar ectopia as a rare cause of brachial neuralgia in adults, and, as pointed out by Drs. Smith and Ridley in their paper, underlines the importance of warning these patients about avoiding trauma to the head or cervical spine.-I am, etc.,

$$
\text { Douglas N. Golding. }
$$

\section{Department of Physical Medicine and Rheumatology,}

Princess Alexandra
Harlow, Essex.

\section{Vasectomy for Sterilization}

SIR,-It seems that, despite the excellent literature distributed by the Simon Trust, there are still a number of surgeons who are not fully conversant with some of the precautions necessary in connexion with this operation. It is essential that patients have seminal specimens examined after the operation until two have been obtained which are free from spermatozoa. In most patients this is about four to five weeks after the operation, although others may take several months. If, however, this has not occurred at the end of three months then the possibility of the presence of a second vas should be suspected. This condition, like congenital absence of the vas, is uncommon. It is obviously of vital importance when a sterilization operation is being performed. If the patient is examined carefully beforehand it is possible to palpate the second vas quite easily, and the operation can still be carried out through the usual small incisions. I have also on one occasion seen a patient where the surgeon had in error ligated the artery instead of the vas. This should not occur if the operation is carried out under proper conditions with adequate lighting in an operating-theatre. It is unwise for it to be performed under lesser circumstances.

Another hazard sometimes overlooked is that patients collect the seminal specimens from a condom. This is a danger, as the presence of a spermicidal substance may be misleading when examining the fluid, especially if the specimen had been sent by post and delayed.

Above all, however, I should like to stress the importance of making sure that the patient realizes that it is essential for him to use normal contraceptive precautions until azoospermia has been proved.-I am etc., 